\title{
Arqueometria em cerâmicas Guarani no sul do Brasil: um estudo de caso
}

\author{
Rafael Guedes Milheira* \\ Carlos Roberto Appoloni * * \\ Paulo Sérgio Parreira**
}

\begin{abstract}
MILHEIRA, R.G. , APPOLONI, C.R., PARREIRA, P.S. Arqueometria em cerâmicas Guarani no sul do Brasil: um estudo de caso. Revista do Museu de Arqueologia e Etnologia, São Paulo: 355-364, 2009.
\end{abstract}

Resumo: Através da análise arqueométrica com uso da técnica de Fluorescência de Raios X (EDXRF) aplicada em amostras de materiais cerâmicos provenientes de sítios arqueológicos Guarani pré-históricos da margem sudoeste da Laguna dos Patos-RS, buscamos discutir aspectos formais das análises tradicionais em arqueologia. É o caso de cerâmicas com a presença de uma "crosta preta" com até cinco milímetros de espessura que ocorre geralmente na superfície externa das peças, cuja análise formal indicava se tratar de traços culturais decorrentes das panelas usadas em contexto sistêmico. No entanto, através da presente análise arqueométrica, conseguimos alcançar resultados mais refinados que indicam outras causas de formação destes traços. Além de discutir os resultados, abordaremos neste texto algumas reflexões sobre a necessidade do uso de técnicas arqueométricas como complementares às análises tradicionais em arqueologia.

Palavras-chave: Arqueologia Guarani - Arqueometria - Cerâmica Fluorescência de Raios X.

\section{Introdução}

$\mathrm{D}$ esde os anos 1960 a arqueologia vem sofrendo profundas mudanças no que se refere ao modo de construção do conhecimento. Estas mudanças trouxeram uma nova

${ }^{*}$ ) Museu de Arqueologia e Etnologia da Universidade de São Paulo. Pesquisador associado ao Laboratório de Antropologia e Arqueologia da Universidade Federal de Pelotas. Bolsista FAPESP. <milheirarafael@gmail.com> $\left.{ }^{* *}\right)$ Departamento de Física, Universidade Estadual de Londrina, Paraná, PR. 〈appoloni@uel.br><parreira@uel.br> tônica à arqueologia, em que as preocupações teóricas de como e por quê explicar o passado humano ressurgiram juntamente a um conjunto de inovações metodológicas decorrentes do desenvolvimento tecnológico do pós-guerra. Em busca de uma crítica ao modelo historicista da arqueologia Histórico-cultural, alguns jovens arqueólogos ingleses e norte-americanos, imbuídos pelo ambiente otimista de mudanças sociais e tecnológicas após a guerra mundial, foram inspirados por novas teorias científicas que surgiam imbricadas a estas inovações tecnológicas (Trigger 2004 [1989]). Num contexto de inovações inspirado pelo surgimento 
do neo-evolucionismo e da teoria dos sistemas, os arqueólogos passaram a questionar a singularidade dos dados arqueológicos e a particularidade histórica e antropológica em explicar o passado e o comportamento humano, resultando no que Clarke (1973) veio a chamar de perda da nobre inocência e crescimento de uma auto-consciência crítica no ambiente da produção do conhecimento arqueológico.

Estas mudanças metodológicas permitiram aos arqueólogos desenvolver uma série de hipóteses sobre aspectos físicos e químicos que caracterizavam os vestígios arqueológicos, chamando atenção para os processos naturais e culturais responsáveis pela conformação do registro arqueológico. Segundo Schiffer (1972) os padrões espaciais do registro arqueológico refletem os padrões das atividades do comportamento das sociedades passadas, enfatizando que a identificação destes padrões no registro arqueológico nos permite compreender aspectos do modo de vida das sociedades humanas no passado. A questão central de seu trabalho não era compreender a variabilidade do registro arqueológico e dos sistemas culturais, mas sim entender por que se forma o registro arqueológico e quais os agentes naturais e culturais que o transformam constantemente. Julgava uma falha dos arqueólogos não compreender e explicar padrões de mudanças pós-deposicionais tanto nos conjuntos artefatuais como na morfologia dos sítios arqueológicos, visto que a "explanação da variabilidade neste domínio não cultural incorpora leis como a quimica, física e geologia" (Schiffer 1972: 156).

Com isto, o autor traz a discussão arqueológica para próximo das ciências químicas, físicas e da terra, articulando ainda mais a interdisciplinaridade na elaboração e aplicação de métodos de coleta, análise de dados e explicação de modelos.

Esta aproximação interdisciplinar abriu espaço para o desenvolvimento de campos hoje concretizados no ambiente de produção arqueológica, como a geoarqueologia e a arqueometria, com suas diferentes abordagens de aplicação a partir de métodos químicos e físicos em arqueologia, coleta, análise de dados e proposição de problemas de pesquisa (ver Schiffer 1987; Araujo 2001).

Se no ambiente acadêmico internacional esta aproximação entre conhecimentos e métodos provenientes da química e física, de um lado, e das ciências arqueológicas, de outro lado, vem se concretizando desde pelo menos os anos 1960, no Brasil, entretanto, somente no fim dos anos 1980 que pesquisas interdisciplinares com essa característica vieram a ser realizadas com maior intensidade (por exemplo, Alves 1988; Alves \& Girardi 1989; Alves et al. 1997; Appoloni et al. 1997; Alves et al. 2000; Munita et al. 2000; Appoloni et al. 2001; Silva et al. 2004; Silva et al. 2005-2006; Goulart et al. 2006; Ikeoka 2009). Este panorama reflete-se também nas temáticas dos trabalhos em congressos e publicações, pois no ambiente acadêmico internacional, sobretudo daqueles países de primeiro mundo, pesquisas arqueométricas são presentes em dezenas de congressos e publicações periódicas. No Brasil, contudo, resultados de pesquisas arqueométricas são menos frequentes nos congressos da Sociedade de Arqueologia Brasileira e quando muito ocorrem em eventos paralelos de outras sociedades ou mesmo de especialistas, logo, sem que haja discussões mais densas entre os arqueólogos e os cientistas que desenvolvem as análises em seus laboratórios de química e física nas universidades brasileiras e centros de pesquisa.

Posto isto, urge a necessidade de que tal abordagem arqueométrica seja mais bem explorada, pois não faltam interesses de pesquisa, nem tampouco pesquisadores no Brasil aptos a trabalhar em parceria com os arqueólogos. A necessidade de pesquisas arqueométricas não deve ser encarada por parte dos arqueólogos como um luxo ou uma simples complementação das leituras analíticas desenvolvidas. Pelo contrário, a importância das análises arqueométricas é tanta que pode colocar em cheque ou mesmo refutar as análises mais tradicionais em arqueologia, com destaque para aquelas abordagens formais a "olho nu".

Em se tratando de materiais cerâmicos, por exemplo, as análises arqueométricas podem 
auxiliar com medições mais precisas das amostras, indicando a composição química da pasta cerâmica, do anti-plástico e dos bancos de argila explorados no ambiente, assim como auxiliar na definição de aspetos deposicionais e pós-deposicionais, tanto de caráter cultural como natural. Logo, este tipo de análise pode auxiliar no entendimento de elementos formais da cerâmica, permitindo com maior precisão caracterizar os atributos de análise relativos aos procedimentos tecnológicos de fabrico, os quais, por sua vez, denotam as escolhas tecnológicas projetadas pelas oleiras no cerne da cadeia operatória.

No presente trabalho, apresentaremos os resultados de um estudo arqueométrico realizado em amostras de fragmentos de cerâmica indígena de grupos Guarani, coletadas no litoral sudoeste da Laguna dos Patos, mais especificamente na margem leste da Ilha da Feitoria, no sítio PT-01-Sotéia (também na mesma ilha) e num sítio arqueológico denominado PS-02-Camping, localizado na praia do Totó, município de Pelotas - RS.

A análise arqueométrica, em nosso trabalho, foi utilizada para tentar explicar a ocorrência de uma "crosta preta" bastante espessa (pode chegar a cinco milímetros em alguns casos), localizada geralmente na superfície externa de alguns fragmentos cerâmicos. A presença da "crosta preta" nos fragmentos cerâmicos, inicialmente foi interpretada da seguinte forma:

a) Poderia se tratar de vestígios de fuligem referentes a marcas de uso das panelas;

b) Uso dos fragmentos de cerâmica que levados ao fogo teriam a mesma função que os materiais líticos encontrados em sítios sem marcas de uso;

c) Deposição dos fragmentos nas fogueiras após a quebra das panelas, gerando uma película preta em função da re-queima e acúmulo de dejetos orgânicos;

d) Poderia ser como uma pasta de coloração preta, posta intencionalmente quando da produção dos potes para impermeabilização dos mesmos, fazendo parte do processo tecnológico de produção; e) ou mesmo, poderia se tratar de um elemento estilístico regional.

Dada tal subjetividade, a ampla gama de hipóteses e a falta de indicadores que permitissem esclarecer a presença desse material na superfície dos fragmentos cerâmicos, consideramos indispensável um estudo arqueométrico que permitisse uma leitura mais objetiva, calcada em uma análise física das amostras. Nesse sentido, a análise a partir da técnica nãodestrutiva de Fluorescência de Raios X (EDXRF) permitiu a identificação dos elementos químicos que compõem a "crosta preta", resultado que iremos apresentar neste texto.

Uma situação semelhante de "crosta preta" foi encontrada em figuras de terracota encontradas em um sítio submerso (Civici 2007), mas cuja origem ainda é uma questão em aberto.

\section{O contexto regional dos sítios arqueológicos}

No litoral sudoeste da Laguna dos Patos foi identificado até o momento um conjunto de sete sítios arqueológicos que sugerem compor um sistema de assentamento regional articulado a um sistema mais amplo que transcende as terras baixas do litoral, alcançando as elevações da serra do Sudeste (Milheira 2008a, 2008b). O sistema litorâneo de sítios arqueológicos Guarani é composto então por, pelo menos, um sítio com a função de aldeia, onde teria havido um aglomerado de pessoas com suas habitações permanentes, cuja datação arqueológica é de $530 \pm 40 \mathrm{AP}$, com data calibrada entre os anos 1390 a 1440 da Era Cristã ou 560 a 510 AP (Beta Laboratory Inc. $n^{\circ}$ 237665). No entorno da Laguna dos Patos ainda foram identificados outros seis sítios arqueológicos de menores dimensões que foram classificados, em termos funcionais, como acampamentos de pesca lacustre, voltados ao abastecimento alimentar da aldeia central do Totó.

Dois destes sítios acampamentos localizam-se na Ilha da Feitoria, a qual é, na verdade, um esporão arenoso de formação 
sedimentar que se situa no interior da Laguna dos Patos e que pelas suas águas baixas e quentes é um criadouro de espécies aquáticas, tornando-se um grande atrativo para pesca, evidenciado pelas ocupações préhistóricas e pela exploração pesqueira atual. Os sítios PT-01-Sotéia e PT-05-Lagoinha evidenciam o interesse e a necessidade dos grupos indígenas Guarani em ocupar as margens da Laguna para exploração.

Além destes sítios, na Ilha da Feitoria identifica-se também uma série de fragmentos de cerâmica depositados na orla da margem leste, cuja coleção procedente de coletas sistemáticas e assistemáticas soma um total de 479 fragmentos de cerâmica e não mais que uma dezena de instrumentos líticos. Sugerimos como hipótese a ser testada por estudos geoarqueológicos, que a ocorrência destes materiais cerâmicos na orla da praia se dê em função da submersão de algum (uns) sítio acampamento, fator este causado pelo aumento recente do nível das águas da Laguna dos Patos, cujo resultado é a formação de uma plataforma sedimentar atualmente submersa, mas que quando os grupos Guarani ocuparam a ilha a mesma estava exposta e formava a margem leste da ilha. Além das cerâmicas encontradas em depósito secundário trazidas pelas águas da Laguna para a orla da praia, outro indicativo deste processo de transgressões das águas é uma carta náutica que apresenta uma plataforma sedimentar em toda margem da Laguna dos Patos, em que na Ilha da Feitoria consta uma plataforma de areia com profundidades entre 1 e 7 metros.

Outro sítio acampamento de interesse no presente trabalho é o PS-02-Camping, também localizado na margem da Laguna, porém, distante da Ilha da Feitoria, a apenas aproximadamente 200 metros da beira da praia. Neste sítio foi evidenciado um contexto arqueológico com uma estrutura de deposição de lixo e uma estrutura de combustão. Esta última é composta por uma vasilha para o cozimento de comida e vestígios de fauna que serviram de alimento. Através da coleta de carvões no interior do pote cerâmico foi possivel datar este contexto através da técnica de AMS em $380 \pm 50 \mathrm{AP}$, sendo a data calibrada colocada numa faixa temporal mais ampla, situada entre os anos 1450 a 1660 da Era Cristã ou 500 a 290 AP (Beta Laboratory Inc., $\left.n^{\circ} 234205\right)$.

\section{Objetivos e dados de análise}

Uma questão importante a tratar no contexto arqueológico que vem sendo estudado na região litorânea de Pelotas e que é o objeto principal deste artigo é a presença de uma "crosta preta" que ocorre na superfície externa de 158 fragmentos e na superfície interna de 81 fragmentos de cerâmica, dentre as 479 peças analisadas que foram coletados na orla da praia da Ilha da Feitoria, assim como em ambas as superfícies de 13 peças do sítio Camping e na superfície externa de cinco fragmentos do sítio Sotéia. Em alguns casos, a "crosta preta" chega a cinco milímetros de espessura e pode até tapar a decoração plástica dos fragmentos.

A "crosta preta" a que nos referimos é uma pasta com uma textura que geralmente se apresenta alisada e demonstra ter um brilho quando exposta à luz, por outro lado, quando a textura é levemente áspera, o material apresenta-se fosco. A olho nu são percebidos alguns grãos de quartzo compondo a pasta, bem como eventualmente se encontram materiais orgânicos como raízes e pequenos vegetais, mas que claramente são intrusões oriundas do ambiente em que estiveram depositadas as peças. É uma pasta facilmente retirada com uma espátula de análise ou pinça, sem que haja qualquer tipo de dano à superfície da peça analisada (Milheira, Appoloni e Parreira 2007; Milheira 2008a).

Inicialmente a "crosta preta" foi interpretada como um material intencionalmente colocado na superfície das peças. Uma espécie de resina com coloração preta que faria então parte de um processo tecnológico. Essa pasta poderia ter a funcionalidade de impermeabilizante, bem como seria um elemento estético indicativo de um aspecto estilístico regional. Essa hipótese passou a ser questionada na medida em que se percebeu que a pasta cobria, em alguns casos, a decoração plástica de alguns fragmentos, ou seja, peças com 


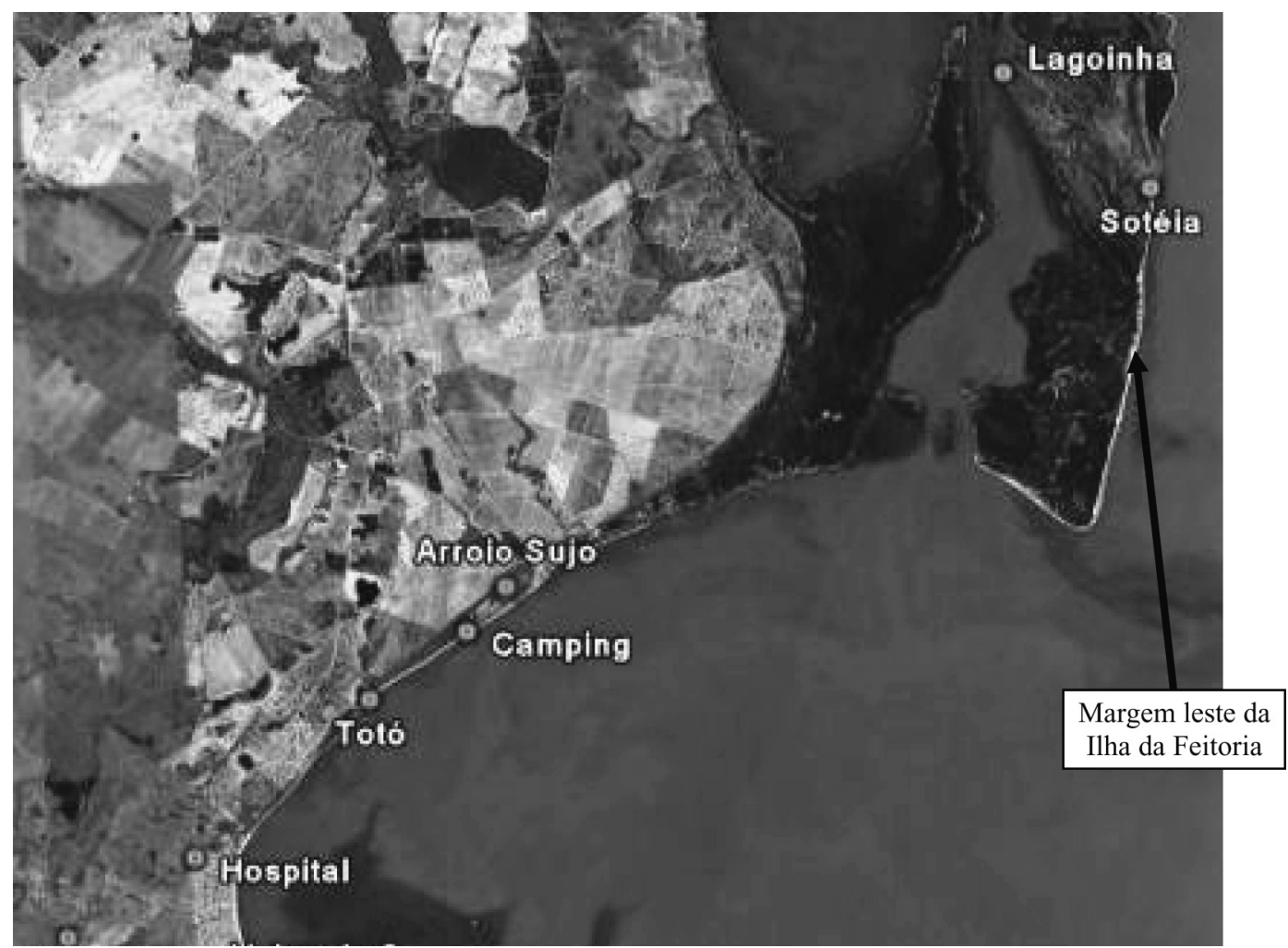

Fig. 1. Distribuição dos sítios arqueológicos sobre foto de satélite na região que compreende a planície sudoeste da Laguna dos Patos, Pelotas-RS (fonte: Google Earth). Destaque para os sítios Camping e Sotéia e para a margem leste da Ilha da Feitoria, de onde provêm as amostras de cerâmica analisadas.

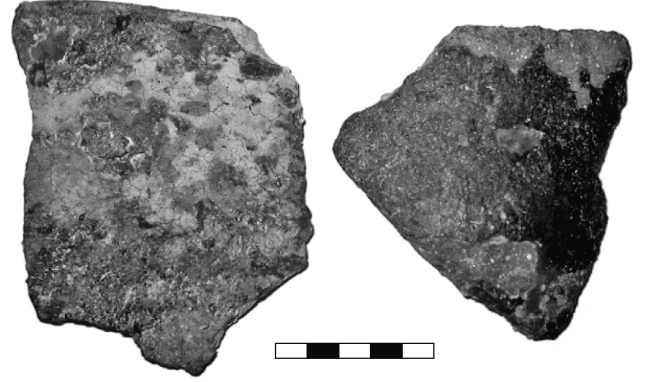

Figs. 2 e 3. Exemplares de fragmentos com "Crosta preta" na superfície externa da cerâmica.

decoração corrugada, corrugada-ungulada ou ungulada, por exemplo, teriam essa marca plástica decorativa da superfície coberta pela pasta preta.

Uma segunda hipótese de trabalho foi pensar na "crosta preta" como fuligem,
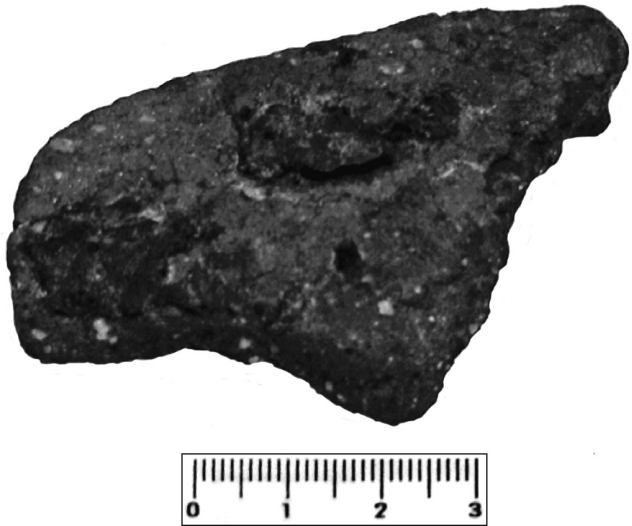

representando então marcas de uso das panelas ou descarte dos fragmentos próximo ou junto ao fogo de modo que formasse uma película preta. É importante frisar que quando ocorre fuligem nas panelas cerâmicas, essa 
geralmente tem uma textura brilhosa semelhante à pasta em questão.

Em virtude da impossibilidade de definir com precisão a ocorrência da "crosta preta" nos fragmentos de cerâmica analisados, percebeu-se que uma análise tradicional não daria conta dessa explicação, sendo necessário partir para outras técnicas analíticas.

A Fluorescência de Raios X por Dispersão em Energia (EDXRF) é um método não destrutivo, que permite a determinação da composição química elementar de amostras, prestando-se bastante bem para análise das crostas e da pasta dos fragmentos cerâmicos citados.

As medidas de EDXRF foram realizadas no Laboratório de Física Nuclear Aplicada da Universidade Estadual de Londrina. O sistema de EDXRF empregado para as medidas é composto por um mini tubo de raios X de $4 \mathrm{~W}$ com anodo de $\mathrm{Ag}$ e filtro de $\mathrm{Ag}$, operando a 28 $\mathrm{kV}$ e $5 \mathrm{~mA}$ e fonte de alimentação FTC 100 , ambos da MOXTEK Inc. Para a aquisição dos dados utilizou-se um detector de Si-PIN (AMPTEK XR $100 \mathrm{CR}$ ), sem colimador, e eletrônica padrão de espectrometria de raios X. O tempo de excitação-detecção foi de 500 s. Os espectros de raios $\mathrm{X}$ foram analisados através do software AXIL.

A amostra que foi processada na análise arqueométrica é composta por sete fragmentos de cerâmica, sendo quatro fragmentos provenientes da orla da praia da Ilha da Feitoria, um do sítio Sotéia e dois do sítio Camping. ${ }^{1}$ Todos os sete fragmentos de cerâmica foram analisados através da técnica de EDXRF. Cada peça foi medida em três pontos na superfície da cerâmica (pasta cerâmica) e em três pontos na superfície da "crosta preta", para que dessa forma se pudessem perceber as variações na composição da "crosta preta" com relação à cerâmica, bem como fosse possivel identificar os componentes e a origem da pasta em questão.

(1) As peças têm os seguintes números de catálogo do LEPAARQ-UFPel: Margem leste da Feitoria (16.592, 16.676, 16.693); Sítio PT-01-Sotéia (58.049); Sítio PS-02Camping (51.1.011, 51.2.124).
Nas medições feitas nos fragmentos provenientes da margem leste da Ilha da Feitoria, notamos a maior variação dos índices de frequência percentual dos elementos químicos que compõem a "crosta preta" com relação à pasta cerâmica.

No fragmento 16.693 foi possível perceber a existência dos elementos $\mathrm{S}, \mathrm{Ca}, \mathrm{Ti}, \mathrm{Mn}$, $\mathrm{Fe}, \mathrm{Ni}, \mathrm{Cu}, \mathrm{Zn}, \mathrm{As}, \mathrm{Br}, \mathrm{Sr}, \mathrm{Y}, \mathrm{Zr}$. Houve aumento percentual de todos esses elementos com relação à cerâmica, mas chama atenção o aumento percentual dos elementos (em ordem decrescente): $\mathrm{Cu}, \mathrm{Br}, \mathrm{As}, \mathrm{Y}, \mathrm{Fe}, \mathrm{Zn}, \mathrm{Sr}$, $\mathrm{Mn}$ e $\mathrm{Zr}$.

Já através da análise realizada no fragmento 16.676 foram identificados os mesmos elementos químicos, mas com frequências percentuais diferentes. Houve um decréscimo dos níveis percentuais, com relação à cerâmica, dos elementos (em ordem decrescente): $\mathrm{Ti}, \mathrm{Mn}$, $\mathrm{Cu}, \mathrm{Sr}, \mathrm{Y}$ e $\mathrm{Zr}$, bem como, por outro lado, houve um aumento nos elementos (em ordem decrescente): Br, Zn, Fe, As e Ni.

No fragmento 16.853 os mesmos elementos foram identificados, porém, com variações nos percentuais de frequência. $\mathrm{O}$ único elemento que decresce em termos percentuais é o Ti, já, todos os demais elementos tiveram um aumento com relação à pasta cerâmica na seguinte ordem crescente: $\mathrm{Ni}, \mathrm{Zr}, \mathrm{Fe}, \mathrm{Zn}, \mathrm{Sr}$, $\mathrm{Mn}, \mathrm{Cu}, \mathrm{As}, \mathrm{Br}, \mathrm{Y}$.

O fragmento 16.592 apresenta uma diminuição do $\mathrm{Ti}$, porém, aumento percentual em ordem crescente dos elementos: $\mathrm{Cu}, \mathrm{Ni}, \mathrm{Fe}$, $\mathrm{Zr}, \mathrm{Mn}, \mathrm{Zn}, \mathrm{Ti}, \mathrm{Sr}, \mathrm{Y}, \mathrm{As}, \mathrm{Br}$.

Nas amostras processadas provenientes do sítio Camping, o fragmento 51.2.124 apresentou aumento nos índices percentuais de todos os elementos (em ordem crescente) $\mathrm{Ni}, \mathrm{Fe}, \mathrm{Sr}$, $\mathrm{Zr}, \mathrm{Mn}, \mathrm{Y}, \mathrm{Zn}, \mathrm{Cr}, \mathrm{Br}$, Cu e As, com exceção apenas para o $\mathrm{Ti}$, que apresentou um decréscimo percentual.

De maneira semelhante, o fragmento 51.1.011 também apresentou os mesmos elementos químicos na sua composição, havendo o crescimento de todos os elementos exceto o $\mathrm{Ti}$, porém, com diferenças percentuais em ordem crescente: Fe, Ni, Sr, Zr, Y, Zn, As, $\mathrm{Cu}, \mathrm{Br}, \mathrm{Mn}$. 


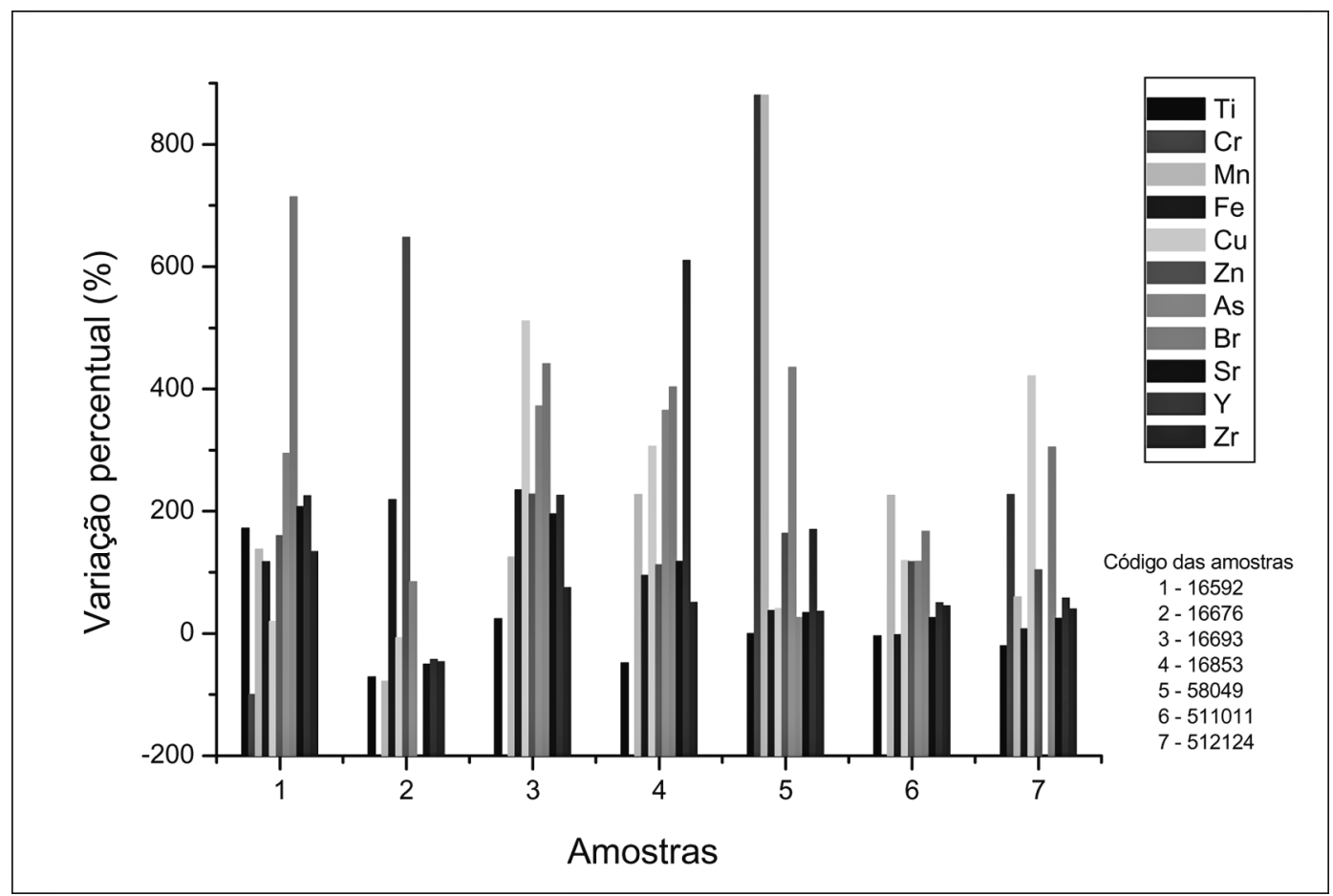

Fig. 4. Gráfico de variação percentual dos elementos químicos das amostras cerâmicas analisadas.

Já, por sua vez, o fragmento 80.049 do sítio Soteia não apresentou em sua composição química o elemento $\mathrm{Cr}$, indicando aumento percentual dos elementos (em ordem crescente) $\mathrm{Ni}, \mathrm{Br}, \mathrm{Sr}, \mathrm{Zr}, \mathrm{Fe}, \mathrm{Cu}, \mathrm{Zn}, \mathrm{Y}, \mathrm{As}, \mathrm{Mn}$.

\section{Discussão dos dados}

Foi possível perceber, através da análise realizada, que a "crosta preta" é claramente de origem inorgânica, face aos elementos identificados e à variação de suas quantidades entre a crosta e a pasta. Se fosse apenas de origem orgânica, tais elementos não estariam presentes e o espectro de energia só apresentaria elementos típicos (e quantidades) da composição da pasta, tais como Fe (devido ao óxido de ferro da argila) e outros correlatos, já que o sistema de XRF empregado (com medidas realizadas no ar) tem sensibilidade para detectar elementos a partir do Enxofre (S).

Percebe-se que a composição da "crosta preta" tem, na maioria das vezes, os mesmos elementos químicos nos fragmentos analisados, mas com percentuais diferentes e bastante variados de ocorrência. Nesse caso, a diferença de percentual é um indicativo de que a composição da "crosta preta" não seja a mesma nos fragmentos, pois caso fosse, teria que haver um aumento e diminuição padronizados dos mesmos elementos químicos com relação à pasta cerâmica. Ao contrário disto, percebeu-se um aumento dos mesmos elementos, mas com variações muito grandes em níveis percentuais. Mesmo nos fragmentos provenientes do sítio Camping, onde o contexto arqueológico é mais bem conhecido e controlado, a variação se mostrou muito grande e esse índice aumenta se compararmos as amostras entre si.

É possivel interpretar então, a partir dos dados apresentados, que um processo natural pós-deposicional atuou sobre os fragmentos cerâmicos. Houve, nesse caso, ao longo dos séculos, a deposição de elementos químicos através da água da Laguna dos Patos sobre os fragmentos cerâmicos, formando uma pasta de 
coloração preta de composição inorgânica e heterogênea no que se refere à frequência dos percentuais de cada elemento com relação à cerâmica. A "crosta preta", sendo considerada um material de origem natural e inorgânica, proveniente da deposição de elementos através da água da laguna, descarta a possibilidade de que se trate de marcas de fuligem ou um fator tecnológico ou estilístico regional.

\section{Conclusões}

O método de Fluorescência de Raios X mostrou-se bastante adequado para análise das amostras. Permitiu não somente identificar os elementos químicos que compõem a "crosta preta" recorrente em dezenas de fragmentos cerâmicos dos sítios arqueológicos, mas também possibilitou avançar na discussão dos processos pós-deposicionais naturais que atuam sobre os materiais arqueológicos no litoral. Ficou claro que os materiais identificados, mesmo que provenientes de contextos arqueológicos distintos, sofreram semelhante ação dos processos naturais relativos ao sistema de transgressões das águas da Laguna ao longo de aproximadamente cinco séculos. Mesmo no caso do sítio Camping onde o contexto arqueológico se mostrou mais bem preservado, as ações das águas da Laguna tiveram impacto semelhante na conformação dos aspectos formais de alguns fragmentos cerâmicos.

No que se refere à "crosta preta" esta composição inorgânica foi facilmente confundida com traços culturais como fuligem ou até mesmo algum tipo de atributo tecnológico para impermeabilização ou embelezamento da panela cerâmica. Esta confusão que decorre da análise a olho nu foi causada não somente por aqueles arqueólogos com pouca experiência, mas também por especialistas em análise cerâmica, demonstrando a necessidade de que análises arqueométricas sejam incorporadas com maior frequência nos métodos de análise tradicionais em arqueologia, sob pena de que as classificações feitas possam ser questionadas com dura intensidade à luz de leituras químicas de fácil acesso.

A definição de que a pasta preta em questão não seja um fator estilístico nem funcional é um dado importante para compreender o contexto arqueológico regional. $\mathrm{Na}$ medida em que os sítios arqueológicos Guarani apresentados neste trabalho são interpretados como acampamentos de pesca e/ou caça, é esperado que os mesmos não tenham cerâmicas com variações estilísticas muito distantes entre si. Nesse sentido, a coleção de fragmentos de cerâmica que compõe a amostra demonstra um mesmo padrão funcional, pois se trata de potes simples destinados ao uso quotidiano, os quais não receberam nenhum tipo de tratamento tecnológico diferenciado daqueles que compõem a coleção da aldeia do Totó, onde a variação estilística dos potes é muito mais acentuada por se tratar de um espaço de maior convívio.

\section{Agradecimentos}

Os autores agradecem a Ricardo M. de Oliveira e Antonio Marcos C. de Moraes, bolsistas $\mathrm{AT} / \mathrm{CNPq}$, pelo trabalho gráfico com os dados para o artigo. 
MILHEIRA, R.G. , APPOLONI, C.R., PARREIRA, P.S. Archaeometry in Guarani ceramic in southern Brazil: a case study. Revista do Museu de Arqueologia e Etnologia, São Paulo: 355-364, 2009.

Abstract: Through the archaeometrical analysis with the X-Ray Fluorescence (EDXRF) technique applied in ceramic material samples from Guarani archaeological sites of the Laguna dos Patos-RS southwest border, we pretend discuss formal aspects in the traditional analysis in archaeology. That's the case of ceramics with a "black crust" with until five millimeters thick that cover normally the external sherds surface, which the formal analysis indicated that it was cultural traces resulting from the pots used in systemic context. However, through the present archaeometrical analysis, we reach most refined results which indicate other causes for the formation of these traces. Besides discuss the results, we'll approach in this text some reflections about the necessity of the archaeometrical techniques uses as complementary to the traditional analysis in archaeology.

Keywords: Guarani Archaeology - Archaeometry - Pottery - X-Ray Fluorescence.

\section{Referências bibliográficas}

ALVES, M.A.

1988 Análise cerâmica: estudo tecnotipológico. Tese de Doutorado, São Paulo: USP.

1997 Estudo de cerâmica pré-histórica no Brasil: das fontes de matéria-prima ao emprego de microscopia petrográfica, difratometria de raios $\mathrm{X}$ e microscopia eletrônica. CLIO. Série Arqueológica, Recife, V. 1, n. 12.: 27-86.

ALVES, M.A.; GIRARDI, V.

1989 A confecção de lâminas microscópias e o estudo da pasta cerâmica. Revista de Pré História, São Paulo, 6: 150-162.

ALVES, M.A.; MUNITA, C.S.; PAIVA, R.P.; MOMOSE, F.; SAIKI, M.

2000 Chemical characterization by INAA of Brazilian ceramics and cultural implications. Journal of Radioanalytical and Nuclear Chemistry, 244 (3): 575-578.

APPOLONI, C.R.; PARREIRA, P.S.; SOUZA, E.; QUACCHIA, J.C.A.; NASCIMENTO FILHO, V.F.; GIGANTE, G.E.; CESAREO, R.; CUNHA E SILVA, R.M.

1997 Estudo de cerâmicas arqueológicas do Paraná por técnicas nucleares não destrutivas. Revista do Museu de Arqueo- logia e Etnologia. São Paulo, Suplemento 2: 135-149.

APPOLONI, C.R.; ESPINOZA QUIÑONES, F.R.; ARAGÃO, P.H.A.; DOS SANTOS A.O.; DA SILVA, L.M.; BARBIERI, P.F.; NASCIMENTO FILHO, V.F.; COIMBRA, M.M.

2001 EDXRF study of Tupi-Guarani archaeological ceramics. Radiation Physics and Chemistry, 61:711-712.

ARAUJO, A.G.M.

2001 Teoria e Método em Arqueologia Regional: Um estudo de caso no Alto Paranapanema, Estado de São Paulo. Tese de Doutorado, São Paulo: USP.

CIVICI, N.

2007 Analysis of Illyrian terracotta figures of Aphrodite and other ceramic objects using EDXRF spectrometry. X-Ray Spectrometry, 36: 92-98.

CLARKE, D.

1973 Archaeology: the loss of Innocence. Antiquity, XLVII: 6-18.

GOULART, E.P.; ALVES, M.A.; FERNANDES, S.C.G; MUNITA, C.S.; PAIVA, R.P.

2006 Caracterização microestrutural e química de amostras de cerâmica pré-histórica do 
sítio Água Limpa, Monte Alto, São Paulo. Canindé, 7: 187-196.

IKEOKA, R.A.

2009 Análise de cerâmicas arqueológicas do sambaqui do Bacanga (São Luís, MA) por EDXRF portátil. Dissertação de Mestrado, Londrina: UEL.

MILHEIRA, R.G.

2008a Território e Estratégia de Assentamento Guarani na Planície Sudoeste da Laguna dos Patos e Serra do Sudeste. Dissertação de mestrado, São Paulo: USP.

2008b Um modelo de ocupação regional Guarani no sul do Brasil. Revista do Museu de Arqueologia e Etnologia, São Paulo, 18: 19-46.

MILHEIRA, R.G.; APPOLONI, C.R.; PARREIRA, P.S.

2007 Análise de Cerâmica Arqueológica Indígena Guarani Através da Técnica de Fluorescência de Raios X (EDXRF). CD ROM de Anais do LASMAC. ISBN 978 85-98196-81-7.

MUNITA, C.S.; PAIVA, R.P.; ALVES, M.A.; OLIVEIRA, P.M.S.; MOMOSE, F.

2000 Contribution of neutron activation analysis to archaeological studies.
Journal of Trace and Microprobe Techniques, 18: 381-387.

SCHIFFER, M.B.

1972 Archaeological Context and Systemic Context. American Antiquity, 37 (2): 156-165.

1987 Formation Processes of the Archaeological Record. Albuquerque: University of New Mexico Press.

SILVA, F.A.; APPOLONI, C.R.; QUIÑONES, F.R.E.; SANTOS, A.O.; DA SILVA, L.M.; BARBIERI, P.F.; NASCIMENTO FILHO, V.F.

2004 A arqueometria e a análise de artefatos cerâmicos: um estudo de fragmentos cerâmicos etnográficos e arqueológicos por Fluorescência de Raios X (EDXRF) e Transmissão Gama. Revista de Arqueologia da Sociedade de Arqueologia Brasileira, 17: 41 - 62.

SILVA, R.M.C. ; NASCIMENTO FILHO, V.F.; APPOLONI, C.R.; PEREZ, C.A.

2005-2006 Fluorescência de Raios X aplicada a amostras arqueológicas. Revista do Museu de Arqueologia e Etnologia, São Paulo, 15-16: 371-382.

TRIGGER, B.G.

2004[1989] História do Pensamento Arqueológico. São Paulo: Odysseus. 